\title{
IMPLEMENTATION OF AUTOMOBILE ASSEMBLY SYSTEM USING AR TECHNOLOGY
}

\author{
PARK, H. S.; CHOI, H. W. \& PARK, J. W.
}

Abstract: Today, increasing global competition demands that automobile manufacturers reduce costs and time in the implementation of manufacturing systems. AR (augmented reality) technology as a new man-machine interface introduces a noteworthy perspective for a new manufacturing system design. Using AR technology, a physically existing production environment can be superimposed with virtual planning objects. Therefore, the planning tasks can be validated without modeling the surrounding environment of the production domain during short process planning timeframes. The architecture of the AR browser is introduced, and the optimal environment parameters for practical application of the AR system are determined through testing. Moreover, methods such as a multi-marker coordinate system, partitioning of virtual objects, and so on, are proposed to solve the problems noted in initial practical tests. Based on these tests and results, a test bed of a cockpit module assembly system is configured and an operation program for cockpit module assembly is generated using the AR system.

Key words: augmented reality system, AR browser architecture, robust superimposition, cockpit module sssembly system
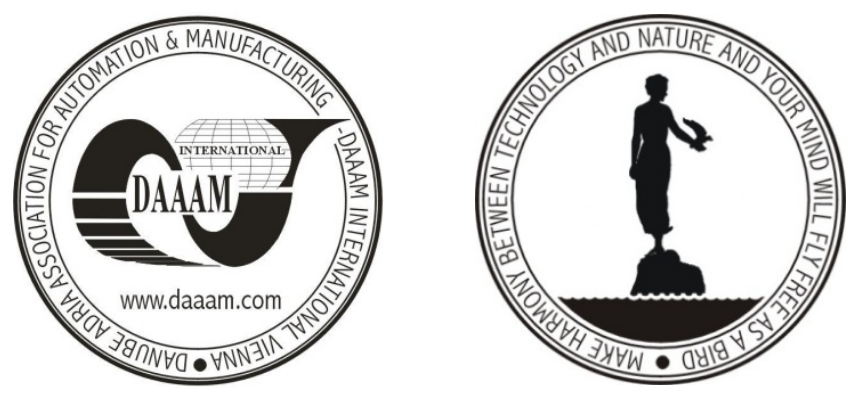

Authors' data: Prof. Dr.-Ing. Park, H[ong] S[eok]; Ph. D. Choi, H[ung] W[on]; Park, J[in] W[oo], University of Ulsan, Daehak-ro 102, Nam-gu, Ulsan, SouthKorea, phosk@ulsan.ac.kr, kuma2008@ulsan.ac.kr, benesarang@mail.ulsan.ac.kr

This Publication has to be referred as: Park, H[ong] S[eok]; Choi, H[ung] W[on] \& Park, J[in] W[oo] (2009). Implementation of Automobile Assembly System Using AR Technology, Chapter 57 in DAAAM International Scientific Book 2009, pp. 587598, B. Katalinic (Ed.), Published by DAAAM International, ISBN 978-3-90150969-8, ISSN 1726-9687, Vienna, Austria

DOI: 10.2507/daaam.scibook.2009.57 